\title{
Interference with Multiplication of Pc Phage by a Factor Produced by Exposure of Pseudomonas aeruginosa to Inactivated Pc Phage
}

\author{
By C. K. MERCER AND R. F. N. MILLS \\ Antibiotics and Biology Divisions, Research Department, \\ Boots Pure Drug Co. Ltd., Nottingham
}

(Received 18 March 1960)

\begin{abstract}
SUMMARY
Pseudomonas aeruginosa strain $\mathrm{C} 10$ when exposed to phage $\mathrm{Pc}$ which had been inactivated by heat or acid produced a factor which decreased the yield of Pc phage in a single cycle of growth on $P$. aeruginosa $\mathrm{C} 10$. Some of the factor appeared in the culture fluid, but most could be obtained only by disrupting the bacteria. The factor did not inactivate free Pc phage. It decreased phage yield most when it was mixed with $P$. aeruginosa $\mathrm{C} 101 \mathrm{hr}$. before infection with $\mathrm{Pc}$ phage and was then kept present to the end of the experiment. When the factor was diluted out immediately after adsorption of Pc phage on $P$. aeruginosa $\mathrm{C} 10$, or when it was present only from the start of adsorption, it had less effect on phage yield.
\end{abstract}

\section{INTRODUCTION}

Isaacs \& Lindenmann (1957) described a substance, which they named interferon, which was produced in tissue cultures by exposure of cells of the chick chorioallantoic membrane to previously inactivated influenza virus. They showed that in tissue culture the yield of influenza virus from the chick chorioallantoic membrane was decreased when interferon was added to the medium. Other authors (e.g. Henle, Henle, Deinhardt \& Bergs, 1959; Ho \& Enders, 1959) described similar substances produced by infecting cell cultures with other animal viruses. It was thought of interest to find whether similar activity could be obtained by exposing bacteria to inactivated phage. This work is reported here.

\section{METHODS}

Media. For preparation of phage stocks the chemically defined medium of Dickinson (1948) supplemented with $0 \cdot 1 \%(w / v)$ acid casein hydrolysate (vitamin free) was used. For all other work a papain digested meat broth was used.

Preparation of phage stocks. $1 \times 10^{8}$ infectious particles of Pc phage (Dickinson, 1954) and $5 \mathrm{ml}$. of a $24 \mathrm{hr}$. $37^{\circ}$ culture of Pseudomonas aeruginosa $\mathrm{C} 10$ in nutrient broth were added to $100 \mathrm{ml}$. defined medium in a $500 \mathrm{ml}$. conical flask. The flask was incubated at $26^{\circ}$ for $12 \mathrm{hr}$. on a rotary shaker. The host bacterium was then killed by heating at $55.5^{\circ}$ for $30 \mathrm{~min}$., and removed by centrifuging at $3600 \mathrm{~g}$ for $6 \mathrm{hr}$. To ensure that no viable bacteria remained, the phage-containing supernatant

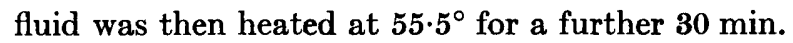

Inactivation of Pc phage. Heat or acid was used for this; ultraviolet irradiation 
proved impractical for technical reasons. For each phage stock, small samples were taken and the minimum treatment required to decrease the titre to less than 10 infectious particles/ml. was determined. This treatment was then used for the bulk of the phage stock.

Production of phage-inhibitory factor. Fifty $\mathrm{ml}$. of a $24 \mathrm{hr}$. broth culture of Pseudomonas aeruginosa $\mathrm{C} 10$ was added to $250 \mathrm{ml}$. of inactivated Pc phage suspension. After incubation at $37^{\circ}$ for $1 \mathrm{hr}$. the bacteria were centrifuged, washed once to remove unadsorbed phage, and then suspended in $50 \mathrm{ml}$. broth and incubated at $37^{\circ}$ for $2 \mathrm{hr}$. They were then centrifuged again and bacteria and culture fluid harvested separately. The culture fluid was heated at $60^{\circ}$ for $30 \mathrm{~min}$. to destroy remaining bacteria. The bacterial pellet was suspended in $5 \mathrm{ml}$. Ringer's solution and stored at $4^{\circ}$ till the organisms were disrupted in a Hughes press cooled to $-20^{\circ}$. After disruption (which was almost complete) the suspension of disrupted organisms was heated at $60^{\circ}$ for 30 min., the bacterial debris removed by centrifuging, and the supernatant fluid harvested.

Tests for activity of phage-inhibitory factor. All tests were made by using single cycles of phage multiplication according to the method of Dickinson \& Codd (1952). Phage yield (measured $2 \frac{1}{2} \mathrm{hr}$. after the start of infection) when the phage-inhibitory factor was present throughout the experiment was compared with phage yield when it was absent throughout. After adsorption the phage was diluted to $c .400$ particles/ ml. Further dilutions were made just before counting, of 1/20 before the burst and $1 / 80$ after it. This final dilution gave convenient numbers for counting (usually c. 200 plaques/plate for controls after the burst); it also diluted out any viable phage in the preparation being tested, and prevented any residual action of the phage-inhibitory factor.

\section{RESULTS}

Inactivation of $P c$ phage. The conditions required to inactivate the four phage stocks are shown in Table 1 . The phage surviving after heat treatment was not inactivated after heating for $300 \mathrm{~min}$. at $65^{\circ}$. The phage stocks treated by acid were shown still to contain viable Pc phage by incubating $5.0 \mathrm{ml}$. samples with Pseudomonas aeruginosa $\mathrm{C} 10$ overnight and then plating out for phage.

Table 1. Conditions for inactivation of pseudomonad phage Pc

\begin{tabular}{|c|c|c|c|c|c|}
\hline \multirow[b]{3}{*}{ Stock } & \multirow{2}{*}{\multicolumn{3}{|c|}{ Treatment }} & \multicolumn{2}{|c|}{ Titre (plaques/ml.) } \\
\hline & & & & & \\
\hline & Temp. & $\mathbf{p H}$ & Time (min.) & $(x$ & \\
\hline 1 & $65^{\circ}$ & $7 \cdot 2$ & 202 & $9 \cdot 6$ & 4 \\
\hline 2 & $67 \cdot 5$ & $7 \cdot 2$ & 210 & 4 & 2 \\
\hline 3 & 20 & $\mathbf{3} \cdot \mathbf{0}$ & 30 & 1.5 & $<1$ \\
\hline 4 & 20 & $\mathbf{2 \cdot 5}$ & 13 & $5 \cdot 9$ & $<1$ \\
\hline
\end{tabular}

Tests for phage-inhibitory activity. Culture fluids were tested undiluted, and disrupted cell preparations at a dilution of $1 / 10$ to correspond to the volume of the culture fluid used. In a preliminary test no activity could be demonstrated with culture fluid when it was added at the time phage and host pseudomonad were first mixed, so for all other tests of activity culture fluid was added to the host organism $1 \mathrm{hr}$. before the phage was added. It was found (Table 2) that preparations 
from the four phage stocks had similar activities; the disrupted cell preparations were much more active than the culture fluids. Fluid and disrupted organisms from a culture of Pseudomonas aeruginosa $\mathrm{C} 10$ untreated with Pc phage were much less active; this culture fluid had no detectable effect, and the disrupted organisms decreased the phage yield only one-half compared with the decrease to one-seventh or less by preparations from organisms exposed to Pc phage.

Table 2. Effect of preparations of phage-inhibitory factor on yield of pseudomonad phage Pc

$\begin{array}{ccc}\begin{array}{c}\text { Preparation } \\ \text { of inhibitor } \\ \text { from stock }\end{array} & \overbrace{\begin{array}{c}\text { Culture } \\ \text { fluid }\end{array}}^{\text {Yield of Pc phage as percentage of control }} & \begin{array}{c}\text { Preparation of } \\ \text { disrupted organisms }\end{array} \\ 1^{*} & 81 & 16 \\ 2 & 72 & 2 \\ 3 & 64 & \text { Not tested } \\ 4 & 70 & 11 \\ \text { Uninfected culture } & 101 & 54\end{array}$

* In this preparation, activity was released into ten times the volume of culture medium used for the other preparations. Preparations were present from $1 \mathrm{hr}$. before the addition of Pc phage to Pseudomonas aeruginosa $\mathrm{C} 10$ to $2 \frac{1}{2} \mathrm{hr}$. afterwards. The yield at $2 \frac{1}{2} \mathrm{hr}$. was compared with that of Pc phage in complete absence of inhibitor preparation. All decreases in yield were significant $(P<0.02$ in Student's ' $t$ ' test $)$.

\section{Mode of action of phage-inhibitory factor}

A few experiments on the mode of action of the phage-inhibitory factor were made by using the disrupted-cell preparations from stock 4 at 1/10 dilution.

Effect on extracellular Pc phage. The phage-inhibitory factor caused no loss in titre of free Pc phage in broth (initial titre $=1 \cdot 7 \times 10^{6} / \mathrm{ml}$.) during $2 \frac{1}{2} \mathrm{hr}$. at $37^{\circ}$.

Effect on multiplication of $P c$ phage. The effect of the phage-inhibitory factor when present throughout the experiment (i.e. from $1 \mathrm{hr}$. before the phage was added) was compared with the effect when it was present only to the end of adsorption. It was found (Table 3, Expt. 1) that a much bigger decrease in yield of phage was obtained when the phage-inhibitory factor was present throughout than when it was present only to the end of the adsorption period. This suggested that prolonged exposure to the phage-inhibitory factor was necessary for it to exert its maximum effect (either because of slow penetration into the host or change within the host to an active form). This suggestion was supported by comparing the effect of preexposing Pseudomonas aeruginosa $\mathrm{C} 10$ to the factor for $1 \mathrm{hr}$. before adsorption with the effect when it was present only from the beginning of adsorption (Table 3, Expt. 2). Unfortunately the inhibitor preparation was less active in this experiment than in previous ones, but it was clear that pre-incubation with the factor did increase its activity.

\section{Other experiments}

The phage-inhibitory factor was tested in a single experiment against $\mathrm{Pa}$ phage (Dickinson \& Codd, 1952), a phage serologically unrelated to Pc phage but growing on the same host; the factor was active against phage $\mathrm{Pa}$. The phage-inhibitory factor was also tested against Newcastle Disease virus in tissue culture by Dr Loïs Dickinson (personal communication) and was inactive. 
Table 3. The effect of phage-inhibitory factor on the multiplication of Pc phage on Pseudomonas aeruginosa $C 10$

All times were measured from the moment of mixing host bacterium and phage. The adsorption period was $10 \mathrm{~min}$. Phage counts were made after dilution by the factors indicated.

\begin{tabular}{|c|c|c|c|}
\hline \multirow{2}{*}{\multicolumn{2}{|c|}{ Factor present }} & \multicolumn{2}{|c|}{ Phage titre } \\
\hline & & \multirow{2}{*}{$10 \mathrm{~min}}$. & \multirow{2}{*}{$\begin{array}{c}2 \frac{1}{2} \mathrm{hr} . \\
(\times 1 / 80)\end{array}$} \\
\hline From & To & & \\
\hline \multicolumn{4}{|c|}{ Experiment 1} \\
\hline $\begin{array}{l}-1 \mathrm{hr} . \\
-1 \mathrm{hr} . \\
\text { Absent }\end{array}$ & $\begin{array}{l}+2 \frac{1}{2} \mathrm{hr} . \\
+10 \mathrm{~min} .\end{array}$ & $\begin{array}{l}14,16,15 \\
11,14,12 \\
12,11,20\end{array}$ & $\begin{array}{l}33,24,25 \\
101,58,73 \\
250,248,245\end{array}$ \\
\hline \multicolumn{4}{|c|}{ Experiment 2} \\
\hline $\begin{array}{l}-1 \mathrm{hr} . \\
0 \mathrm{hr} . \\
\quad \text { Absent }\end{array}$ & $\begin{array}{l}+2 \frac{1}{2} \mathrm{hr} \\
+2 \frac{1}{2} \mathrm{hr}\end{array}$ & $\begin{array}{l}16,15,19 \\
19,19,14 \\
13,9\end{array}$ & $\begin{array}{l}107,133,134 \\
263,220,270 \\
250,260,288\end{array}$ \\
\hline
\end{tabular}

\section{DISCUSSION}

The phage-inhibitory factor described here resembles interferon (Isaacs \& Lindenmann, 1957 ; Lindenmann, Burke \& Isaacs, 1957) in some ways : it is produced by the host cells in response to virus inactivated by very mild treatment; it does not inactivate free virus; it needs time to exert its full inhibitory effect; its activity is not restricted to the virus which caused its production. The phage-inhibitory factor differs from interferon in its greater stability to heat. It also is not liberated readily from the host bacteria, whereas interferon passes easily into the culture medium, but this may merely reflect the difference between the cell walls of bacteria and the chick chorioallantoic membrane.

We wish to thank Dr Loïs Dickinson for advice and criticisms during this work, and Drs M. Lumb and G. Woolfe for their interest and encouragement.

\section{REFERENCES}

Dickinson, L. (1948). The bacteriophages of Pseudomonas pyocyanea. 1. The effect of various substances upon their development. J. gen. Microbiol. 2, 154.

Dickinson, L. (1954). The behaviour of a temperate phage of Pseudomonas aeruginosa compared with that of a serologically related, virulent mutant. J. gen. Microbiol. 11, 105.

Dickinson, L. \& Codd, S. (1952). The bacteriophages of Pseudomonas pyocyanea. 2. Bacteriophage reproduction in an iridescent strain. J. gen. Microbiol. 6, 1.

Henle, W., Henle, G., Dernhardt, F. \& Bergs, V. (1959). Studies on persistent infections of tissue cultures. IV. Evidence for the production of an interferon in MCN cells by myxoviruses. J. exp. Med. 110, 525 .

Ho, M. \& Enders, J. F. (1959). An inhibitor of viral activity appearing in infected cell cultures. Proc. nat. Acad. Sci., Wash. 45, 385.

Isaacs, A. \& Lindenmann, J. (1957). Virus interference. 1. The interferon. Proc. roy. Soc. B, 147, 258.

Lindenmann, J., Burke, D. C. \& IsaAcs, A. (1957). Studies on the production, mode of action and properties of interferon. Brit. J. exp. Path. 38, 551. 